\title{
Physiological Responses of Hybrid Striped Bass to Aqueous Copper in Freshwater and Saltwater
}

\author{
G. K. Bielmyer, ${ }^{1}$ J. Tomasso, ${ }^{2}$ S. J. Klaine ${ }^{3}$ \\ ${ }^{1}$ Department of Marine Biology and Fisheries, University of Miami, 4600 Rickenbacker Cswy., Miami, Florida 33149, USA \\ ${ }^{2}$ Department of Aquaculture Fisheries and Wildlife, Clemson University, G08 Lehotsky, Clemson University, South Carolina 29634, USA \\ ${ }^{3}$ Department of Environmental Toxicology, Clemson University, 509 Westinghouse Rd., Pendleton, South Carolina 29670, USA
}

RE: Arch Environ Contam Toxicol 50, 531-538 (2006) [this issue]: Incorrect units appear in the abstract of the published print and online versions of this article. In the abstract, the units "mg" should be replaced with " $\mu \mathrm{g}$ ". The corrected abstract appears here.

\begin{abstract}
Copper $(\mathrm{Cu})$ is an abundant trace metal, and although essential at low levels, it is also potentially toxic to aquatic organisms. Mechanisms of toxicity and consequences of exposure vary depending on ionoregulatory status (acclimated to freshwater or salt water). The goal of this research was to examine the responses of hybrid striped bass (Morone chrysops $\times$ Morone saxatilis) exposed to $\mathrm{Cu}$ in freshwater and $15 \mathrm{~g} / \mathrm{L}$ salt water. In freshwater, a general dose- and timedependent pattern of increasing $\mathrm{Cu}$ accumulation in gill tissue was evident in fish exposed to aqueous $\mathrm{Cu}$ (220 and $447 \mu \mathrm{g} /$ L) for up to 96 hours. The 96-hour acute median lethal concentration for freshwater-acclimated hybrid striped bass
\end{abstract}

exposed to $\mathrm{Cu}$ was $94 \mu \mathrm{g} / \mathrm{L}$ (confidence interval $=62$ to 144 $\mu \mathrm{g} / \mathrm{L})$. Plasma osmolality and $\mathrm{Na}^{+}$concentrations decreased in $\mathrm{Cu}$-exposed fish. Freshwater-acclimated hybrid striped bass exposed to aqueous $\mathrm{Cu}(60 \mu \mathrm{g} / \mathrm{L})$ for 3 weeks decreased in mass and accumulated $\mathrm{Cu}$ in gill, intestine, and liver. In salt water, no mortality occurred, and there were no statistical differences in growth, tissue $\mathrm{Cu}$, or plasma ion concentrations in hybrid striped bass exposed to $\mathrm{Cu}$ compared with control fish. Freshwater-acclimated hybrid striped bass were very sensitive to $\mathrm{Cu}$ exposure and exhibited responses typical of commonly tested teleost fishes; however, the same sensitivity was not observed in salt water-acclimated fish. 